\title{
Controlling mine pressure by subjecting high-level hard rock strata to ground fracturing
}

\author{
Rui Gao ${ }^{1,2} \cdot$ Tiejun Kuang ${ }^{2} \cdot$ Yanqun Zhang $^{2} \cdot$ Wenyang Zhang ${ }^{2} \cdot$ Chunyang Quan ${ }^{2}$
}

Received: 7 September 2020/Revised: 8 October 2020/Accepted: 31 December 2020/Published online: 23 January 2021

(C) The Author(s) 2021

\begin{abstract}
When mining extra-thick coal seams, the main cause of strong ground pressure are the high-level thick and hard strata, but as yet there is no active and effective control technology. This paper proposes the method of subjecting hard roofs to ground fracturing, and physical simulation is used to study the control effect of ground fracturing on the strata structure and energy release. The results show that ground fracturing changes the structural characteristics of the strata and reduces the energy release intensity and the spatial extent of overburden movement, thereby exerting significant control on the ground pressure. The Datong mining area in China is selected as the engineering background. An engineering test was conducted on site by ground horizontal well fracturing, and a 20-m-thick hard rock layer located $110 \mathrm{~m}$ vertically above the coal seam was targeted as the fracturing layer. On-site microseismic monitoring shows that the crack propagation length is up to $216 \mathrm{~m}$ and the height is up to $50 \mathrm{~m}$. On-site mine pressure monitoring shows that (1) the roadway deformation is reduced to $100 \mathrm{~mm}$, (2) the periodic weighting characteristics of the hydraulic supports are not obvious, and (3) the ground pressure in the working face is controlled significantly, thereby showing that the ground fracturing is successful. Ground fracturing changed the breaking characteristics of the high-level hard strata, thereby helping to ameliorate the stress concentration in the stope and providing an effective control approach for hard rock.
\end{abstract}

Keywords Ground fracturing $\cdot$ High-level hard roof $\cdot$ Breakage characteristics $\cdot$ Pressure control $\cdot$ Safety mining

\section{Introduction}

The main coal seams for high-efficiency mining are thick and extra-thick ones, for which caving mining is mainly used at present. However, the large thickness of thick and extra-thick coal seams means that the range of overburden migration is wide. Previous studies have shown that the overburden failure zone can exceed $250 \mathrm{~m}$ when mining 14-20 m thick coal seams (Yu et al. 2015, 2017; Zhang

Rui Gao

gaorui@tyut.edu.cn

Tiejun Kuang

kuangtiejun@163.com

1 College of Mining Engineering, Taiyuan University of Technology, Taiyuan 030024, Shanxi, China

2 Jinneng Holding Group, Datong 037000, Shanxi, China et al. 2014; Zuo et al. 2019). When the overburden has multiple hard roofs, their breaking at different levels results in the frequent presence of strong ground pressure in the stope, which damages roadways, causes supports to crash, and seriously affects safe production (Guo et al. 2014; Yang et al. 2015; Xia et al. 2017; Cheng 2019; Bandyopadhyay et al. 2020).

Given the strong ground pressure when mining extrathick coal seams with hard roofs, scholars have conducted related research. Yu (2016) studied the mechanism for strong mine pressure in a Datong coal mine and noted that the high-level hard thick strata were the main cause of the strong pressure in the mining stope. Bednarek and Majcherczyk (2020) discussed the rock mass characteristics, which influence the choice of support. Ning et al. (2017) and Wang et al. (2019) analyzed the fracturing characteristics of overlying hard roofs by means of microseismic monitoring, which could assist in explaining 
the strong strata behavior induced by thick and hard roofs. $\mathrm{Ju}$ and Xu (2013) analyzed the structural characteristics of overlying hard strata and the ground pressure in a stope following the mining of a 7-m-thick coal seam. Xie and Xu (2017) analyzed the law governing how different thicknesses and distributions of hard roofs influenced the peak value and influence range of the leading abutment stress of a working face. Li et al. (2018) showed that the rotary movement of the key strata in an overburden had a direct impact on the appearance of pressure on the supports in a working face, and they analyzed how the rotary angle of the key strata in different levels influenced the stope pressure. Li et al. (2014) found that the large mining thickness of an extra-thick coal seam resulted in a larger mobile space of the high-level hard roofs, and this sliding instability of the high-level hard roofs induced a strong ground pressure. Lan et al. (2018) used in situ measurements to compare the support resistance in the working face when mining an extra-thick coal seam. They found that the weight characteristic exhibited "long" and "short" durations. When a high-level hard roof broke, the mine pressure increased, but there was no obvious regularity in the breaking of the high-level hard strata. Finally, Tan et al. (2018) studied the capability of coal seams influenced by overlying hard roofs.

The above studies showed that when mining an extrathick coal seam, if the overburden deposits hard roofs, then the large suspended area of those hard roofs is the main factor causing strong ground pressure in the working face. In particular, the breakage and instability of the high-level hard and thick strata were identified as the main reasons for the rock mass failure and extremely high bearing stress of the coal body.

Active weakening is the main technical approach to reducing the breaking strength of hard roofs. At present, hydraulic fracturing and confined water-filled blasting are adopted primarily. Fracturing pumps, fracturing pipes, grooving drill bits, and other equipment are used to fracture roofs in the process of hydraulic fracturing to reduce the integrity of the roofs and achieve the goal of ground pressure control ( $\mathrm{Lu}$ et al. 2015; Ge et al. 2015; Yu and Duan 2014). By using liquid explosive, confined waterfilled blasting technology can not only realize safe blasting but also improve the blasting ability to the maximum extent to reduce the breaking strength of hard roofs (Yang et al. 2017; Yang and Liu 2017; Wang et al. 2020). However, constrained by the equipment, drilling hole length, and other conditions, the above technologies are limited to underground operation only, and the control range is within $50 \mathrm{~m}$, which cannot fracture hard roofs at high level. Therefore, $\mathrm{Yu}$ and colleagues proposed the method of ground hydraulic fracturing for the first time ( $\mathrm{Yu}$ et al. 2019; Gao 2018), i.e., fracturing the target roofs at high level by drilling fracturing wells downward from the ground. In the fracturing process, only clean water was used, which was economical and environmentally friendly. Simultaneously, the fracturing control range was large and the control effect was good.

Only a few scholars have studied ground fracturing (GF) technology. Yu et al. (2019) proposed the method and applied it in the field for the first time, achieving excellent control. Aimed at selecting the target layers for GF, Lu et al. (2018) compared and analyzed the breaking strength of hard roofs at different levels and determined a reasonable range of GF layers via numerical simulation. Regarding the ground pressure control mechanism and strata structural morphology of GF, scholars are yet to conduct in-depth research. Physical similarity simulation is a research method that can accurately and intuitively reflect the overburden structural characteristics (Yan et al. 2018). In the study, this method is used to conduct an in-depth investigation of the characteristics of the overburden displacement and strata breaking strength of high-level roofs after GF to reveal the weakening mechanism of GF. A field-application verification is conducted to improve the technical system for subjecting a high-level hard roof to GF.

\section{Proposed method of ground hydraulic fracturing}

\subsection{Background}

In the Tashan Coal Mine in the Datong mining area, the main mining is that of the extra-thick coal seam numbered $3-5$. The coal seam thickness is $14-20 \mathrm{~m}$, and the method of top-coal caving mining is adopted. The coal seam is buried at a depth of 400-800 m, and there are multiple hard roofs in the overburden with a compressive strength of 60-120 MPa. When mining the working face, a strong ground pressure occurs periodically, and the characteristics are reflected mainly in the following aspects.

(1) The first roof weighting step of the working face is $46-55 \mathrm{~m}$. The periodic weighting of the working face is reflected in the aspects of short, long, and extremely strong weightings.

(2) Short weighting period: the roof weighting step is $12-26 \mathrm{~m}$, which is manifested mainly in the increased resistance of 20-30 supports of the working face. There is obvious rib spalling of the coal wall, and the top coal is easily caved.

(3) Long weighting period: the roof weighting step is $30-52 \mathrm{~m}$, the resistance of more than 40 supports of the working face increases sharply, and the safety 
valves are opened substantially. The rib spalling of the coal wall is significant, and the top coal is liable to fall off. The roadway deformation near the working face exceeds $2000 \mathrm{~mm}$.

(4) Extremely strong weighting period: there is no obvious weighting step, and the occurrence frequency is low. During the period, the shield supports in the working face are frequently crushed, the minimum size of the roadway is only $1000 \mathrm{~mm} \times$ $1000 \mathrm{~mm}$, and the advanced single hydraulic props are severely bent and split.

To explore how hard-roof failure and instability at different levels influences the appearance of pressure on a stope, field measurements were performed in the Tongxin coal mine of the Datong mining area (Lan et al. 2018). In that case, the thickness of the No. 3-5 coal seam was $19 \mathrm{~m}$, and the method of top-coal caving mining was adopted. The strata-movement measurement points were arranged in the key strata at different levels $(22,51$ and $104 \mathrm{~m}$ above from the coal seam). The thicknesses of the three key strata were 12.0, 9.8, and $23.0 \mathrm{~m}$ from the bottom up. Concurrently, the resistances of the shield supports in the working face were recorded in real time. The monitoring results showed that the support resistance increased with the breakage of two key strata that were 22 and $51 \mathrm{~m}$ above the coal seam at a low level, and the load coefficient of the supports was 1.15 and 1.34 , respectively. The pressure duration was 7 and $16 \mathrm{~h}$, respectively, and there were no obvious indications of strong ground pressure in the working face. When a 23-m-thick key layer (which was $104 \mathrm{~m}$ from the coal seam) broke, the No. 35-95 supports in the working face were crushed (the working resistance of a hydraulic support in the working face was $15,000 \mathrm{kN}$, and the yield resistance was $17,000 \mathrm{kN}$ ), and the load coefficient of the support reached 1.54. The pressure duration reached $43 \mathrm{~h}$, and the ratio of the distance between the highest key layer and coal seam to the coal seam thickness was 5.47. As can be seen, when mining an extra-thick coal seam, if there is a thick and hard roof at a high level, then its failure and instability result easily in a strong impact strength, which is the main factor inducing the strong ground pressure in the working face, as shown in Fig. 1.

\subsection{Technology of ground hydraulic fracturing}

The presence of hard roofs at a high level is the main factor that causes the strong ground pressure in the working face. Furthermore, a large breaking step and an entire block rotation are the internal inducements of the strong ground pressure. Therefore, using a reasonable technology to weaken the hard strata in far fields and change their

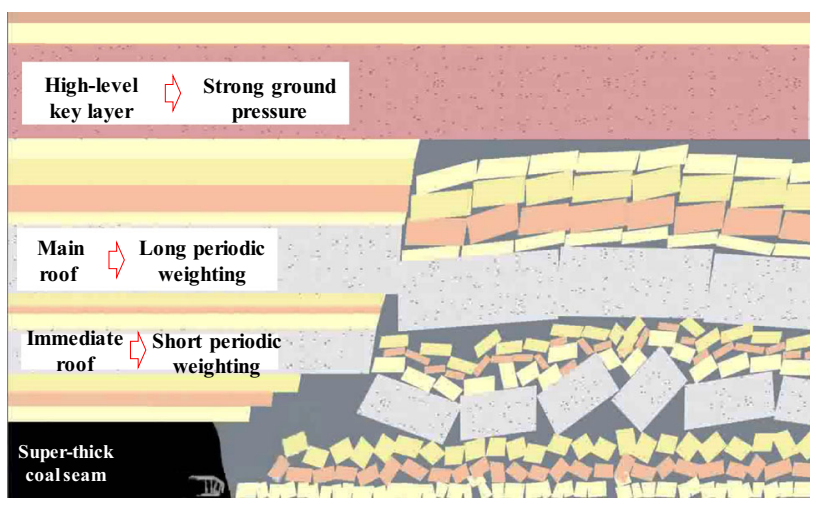

Fig. 1 Strata structure and corresponding ground pressure

physical and mechanical properties, structural occurrence, and fracture characteristics-thereby reducing the breaking strength of the hard roofs and modifying the stress concentration in the stope-is an effective approach to preventing strong ground pressure.

Years of research and practice have led to a set of hardroof control technologies based on underground hydraulic fracturing and blasting (Lu et al. 2015; Ge et al. 2015; Yu and Duan 2014; Yang et al. 2017; Yang and Liu 2017), which are effective for controlling hard roofs at a low level near the coal seam underground. However, the limitations of the underground hydraulic fracturing equipment, technology, and construction conditions mean that it is generally only possible to weaken hard roofs that are less than $50 \mathrm{~m}$ above from the coal seam, and it is impossible to control those at a high level.

Drilling GF technology is used widely to exploit oil and gas, the principle being to use a hydraulic pump to create cracks of a certain geometric size and conductivity artificially. Therefore, with reference to GF technology, we innovatively proposed subjecting the hard roofs in a coal mining area to GF. Moreover, GF equipment is used to weaken high-level hard rock formation to reduce the integrity and strength of the hard roofs and achieve ground-

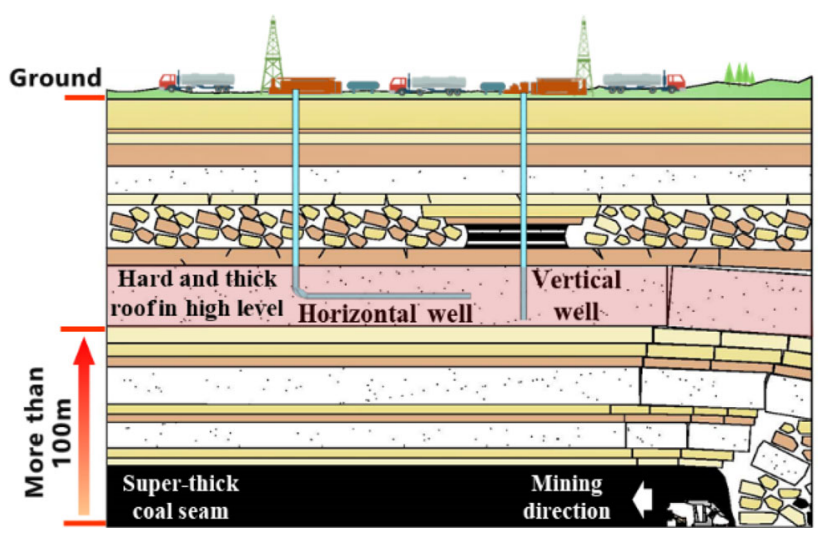

Fig. 2 Ground hydraulic fracturing of high-level hard roofs 
pressure control (Yu et al. 2019; Gao 2018). The idea is shown schematically in Fig. 2.

Previous work has shown that hydraulic fractures propagate perpendicular to the minimum principal stress and parallel to the maximum principal stress (Sampath et al. 2017). However, affected by the complex stress distribution of underground rock formations, the propagation of cracks is uncertain, and complex cracks may appear with horizontal, vertical, or other forms.

\section{Simulation of ground pressure control by ground fracturing}

Water is mainly used to subject hard roofs to GF. The direction of fracture propagation is related directly to the distribution of the in situ stress field in the rock deformation. After fracturing, the crack distribution in the strata can be divided into three situations: (1) the formation of one or more horizontal cracks that reduce the effective thickness of the strata and divide the complete rock layer into two or more layers; (2) the formation of a vertical crack that cuts the thick and hard roof into two independent structures; (3) the formation of numerous disordered cracks that destroy the integrity of the thick and hard rock strata, dividing them into several sections. Herein, the length limitation means that only the influence of vertical-crack occurrence on the characteristics of the overburden structure and ground pressure is discussed. By performing a physical similarity simulation, a vertical crack is generated artificially in the high-level hard roof of the model. By comparison and analysis with a non-fracturing model, the overburden structural characteristics and the rule governing the variation of the ground pressure are studied.

\subsection{Physical model}

Taking the 8101 working face in the Tashan coal mine as the reference for the physical model, we build two models in total. Model 1 is built according to the geological conditions, and model 2 is based on model 1 but with a vertical crack created artificially in the high-level hard roofs. The carboniferous No. 3-5 coal seam is mined mainly in the 8101 working face, and the average thickness, buried depth, and inclination angle of the coal seam are $20 \mathrm{~m}$, $470 \mathrm{~m}$, and $1^{\circ}-3^{\circ}$, respectively. The working face is $230-\mathrm{m}$ long, and the continuous mining length is around $1500 \mathrm{~m}$. The coal seam is covered with multiple layers of hard roofs. The geometric size of the physical similarity model is $2.5 \mathrm{~m} \times 0.2 \mathrm{~m} \times 1.47 \mathrm{~m}$ (length $\times$ width $\times$ height). The similarity ratio of the model is $150: 1$, and the simulated laying height is $220 \mathrm{~m}$.
Sand, calcium carbonate, and gypsum were used in the laboratory for modeling, and the designed bulk density ratio is $1.667: 1$. The motion time similarity ratio, stress similarity ratio, and dynamic similarity ratio are calculated to be $12.25: 1250: 1$, and $5.63 \times 10^{6}: 1$, respectively. The model was excavated continuously to the boundary every $30 \mathrm{~min}$, with $5 \mathrm{~cm}$ excavated each time. The thickness of the overlying unarranged rock layer is $272.65 \mathrm{~m}$, and the compensation stress added to the upper part of the model is calculated to be $0.027265 \mathrm{MPa}$. The boundary on each side of the model was fixed to generate a certain horizontal stress. The matching parameters of the rock layers obtained in the model are listed in Table 1; the key strata are the rock formations numbered $32,27,22,16$, and 9 , which are recorded as KS1 -5 , respectively. In this experiment, KS5 at a high level is mainly studied.

In model 2, to reduce the integrity of KS5, a crack was set artificially therein at $90 \mathrm{~m}$ horizontally from an openoff cut by a thin iron piece. A prefabricated crack was formed in the model by placing a $0.2-\mathrm{mm}$-thick piece of iron in the fractured target layer. Because the model was 20 -cm wide, two $10 \mathrm{~cm} \times 10 \mathrm{~cm}$ thin iron sheets were used. The model and fracture setting scheme are shown in Fig. $3 a, b$ shows the scheme used to monitor the overburden displacement. A Vic-2D noncontact strain monitoring system was used; black speckles were sprayed on the surface of the model, and the displacement of the overlying strata was obtained by monitoring the displacement of each scattered black point.

\subsection{Analysis of results}

\subsubsection{Characteristics of overburden structure after ground fracturing}

The structural characteristics of the high-level KS4 and KS5 are analyzed. The structural characteristics of KS4 and KS5 before and after KS5 is fractured are shown in Fig. 4.

As shown in Fig. 4a, c, when the high-level KS5 is not fractured, the breaking span of KS4 and KS5 is 170 and $175 \mathrm{~m}$, respectively. The breakage of KS4 and KS5 causes an unstable and synchronous rotation of the lower strata, and the range of the motion space in the overburden is wide. The vertical displacement of the cantilever beam structure close to the working face caused by the breakage of KS5 and KS4 is 0.48 and $2.5 \mathrm{~m}$, respectively.

After KS5 is fractured, the first breaking step of the high-level KS4 is reduced to $142 \mathrm{~m}$, of which the length of broken block A is only $47 \mathrm{~m}$, and the displacement of the immediate roof at the working surface is $0.45 \mathrm{~m}$, as shown in Fig. 4b. Compared to the KS5 unfractured model in Fig. 4a, the KS4 breaking span is reduced after KS5 is fractured; this is mainly because the bearing capacity of 


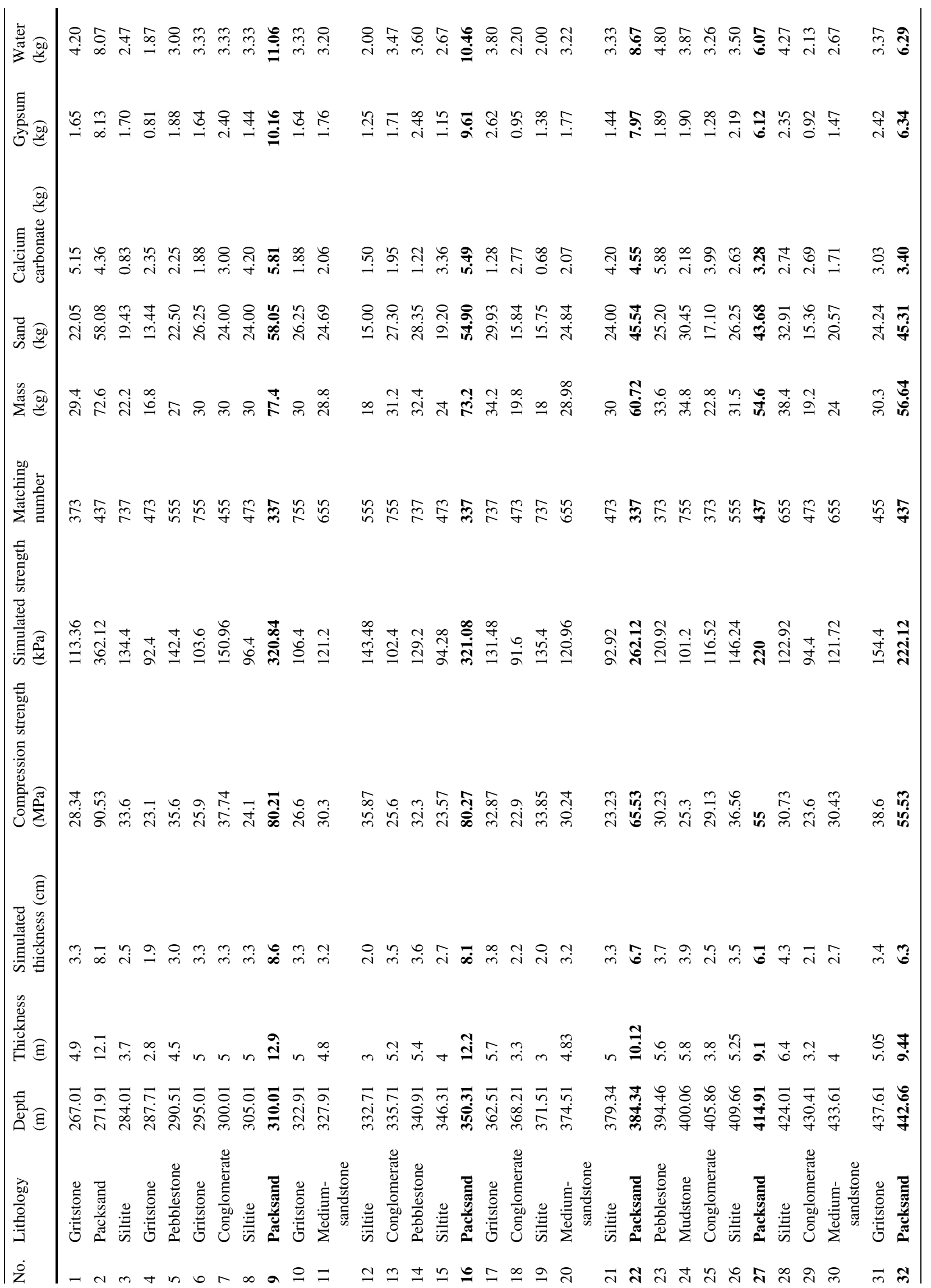




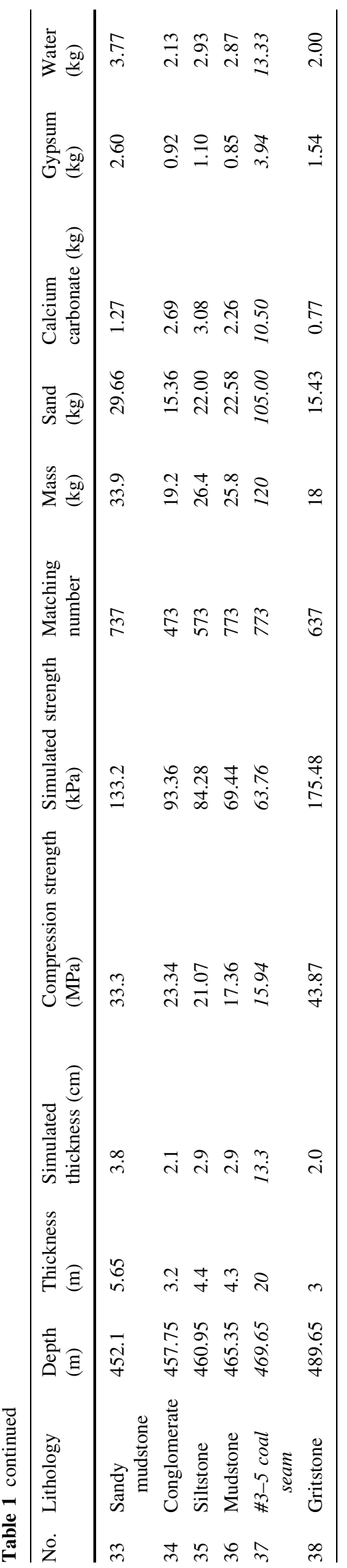

KS5 is reduced after fracturing. Moreover, the loads of KS5 and its overlying strata are transferred to KS4, increasing the load acting on KS4 and thereby decreasing the breaking step. It can also be seen from Fig. 4b that after KS4 is broken, KS5 also undergoes a large degree of deflection and rotation by the fracturing action, but it does not rotate synchronously with KS4 and still maintains a certain structural stability.

As mining of the working face continues, KS5 continues to rotate. However, its relatively slow rotation means that the breaking and unstable energy release intensities are low and have no impact on the underlying strata; the underlying key layer structure remains stable. The rotation of the KS5 breaking block does not generate a ground pressure, as shown in Fig. 4d.

\subsubsection{Strata movement control by ground fracturing}

Taking KS4 and KS5 as the research objects, the vertical displacement was obtained during the breakage of KS4 and KS5 under the conditions of the occurrence and non-occurrence of KS5 fracturing, as shown in Fig. 5. The abscissa represents the positions of the measurement points along the mining direction.

As shown in Fig. 5a, in the absence of KS5 fracturing, when KS4 breaks, the maximum vertical displacement of KS5 is $1.2 \mathrm{~m}$, and the KS5 structure remains stable. After KS5 is fractured, when KS4 breaks, the KS5 structural integrity is reduced, being affected by the weakening of the GF, and a large bending subsidence of $1.73 \mathrm{~m}$ occurs in KS5. However, the KS5 structure does not sink with KS4 synchronously, and it can maintain structural stability and a certain separation space with the underlying rock formation. As mining of the working face continues, KS5 settles slowly to stability.

It can be seen from Fig. 5b that when KS5 is not subjected to GF, its integrity is strong, and the breaking span is $175 \mathrm{~m}$. The large rotary movement and high strength during KS5 breakage causes a synchronous movement of the underlying strata. Taking KS4 as an example, KS5 breakage causes the vertical displacement of KS4 to reach $1.68 \mathrm{~m}$. When KS5 is fractured, its rotation is no longer a fast high-intensity movement process but one of slow deflection and sinking. The strength and energy release during KS5 breakage are low, which has a weak impact on the underlying rock formation. The rotation of KS5 after GF barely causes synchronous movement of the underlying rock formation, the vertical displacement of KS4 hardly changes, and the KS4 structure remains stable. As can be seen, the GF reduces significantly the strength of the hardstrata movement.

In addition, after KS5 is fractured, its reduced bearing capacity means that KS4 bears some of the overburden 


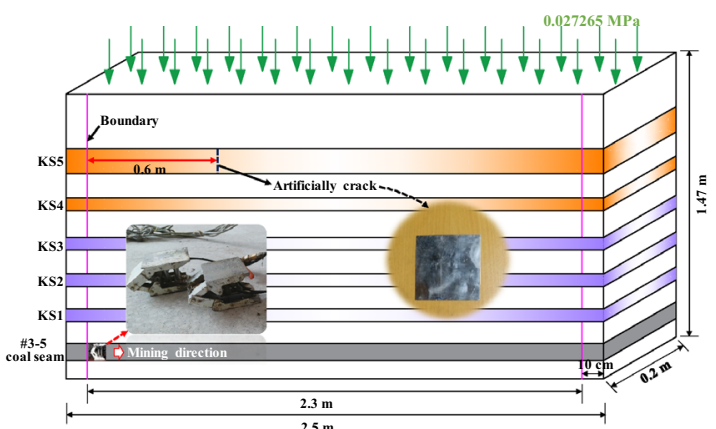

(a)

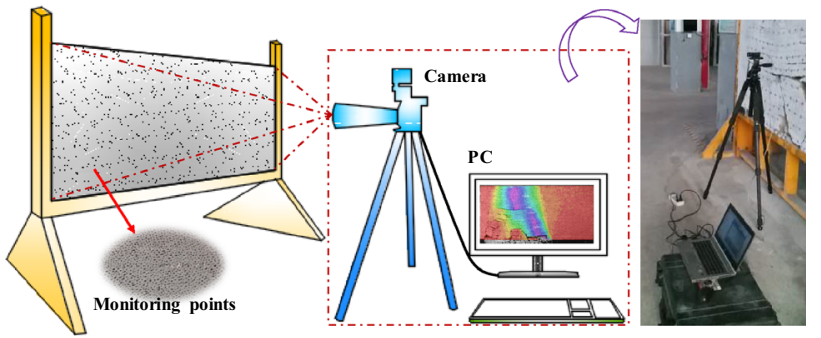

(b)

Fig. 3 Physical model layering and monitoring scheme: a model diagram; b schematic of displacement monitoring

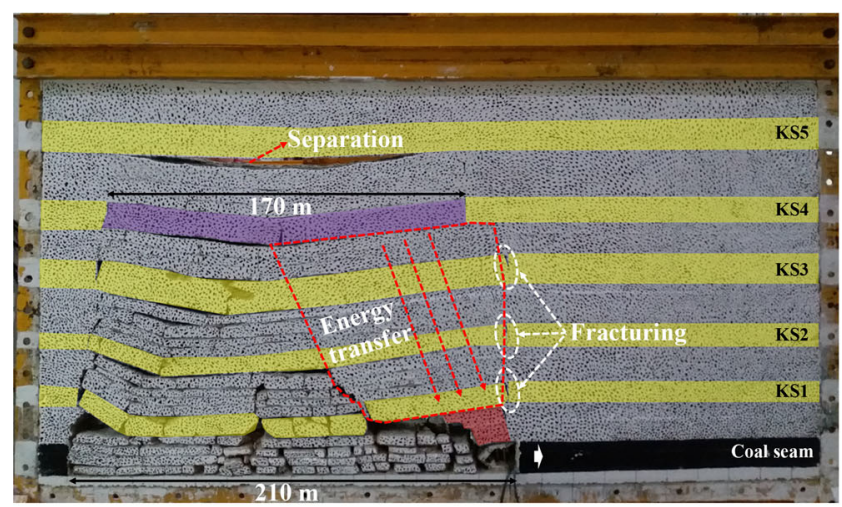

(a)

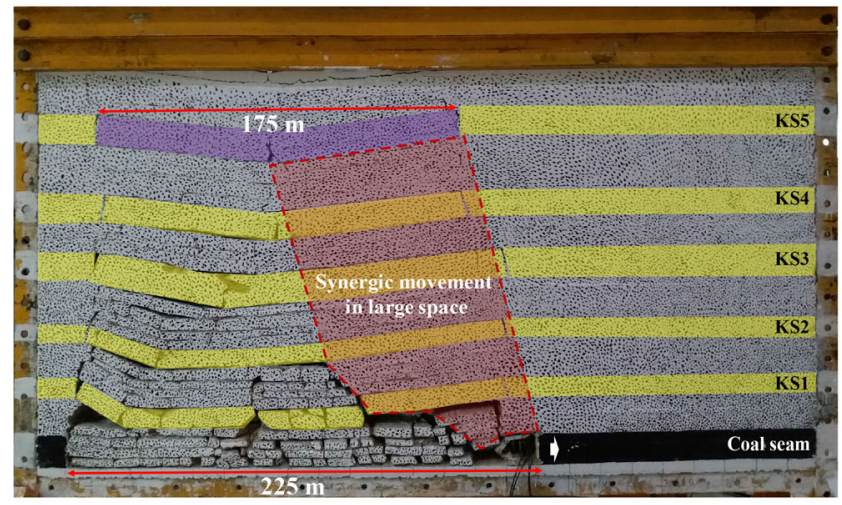

(c) weight, thereby increasing the load acting on KS4 and decreasing the KS4 breaking step. In the experiment, it was found that the KS4 breaking step reduced to $142 \mathrm{~m}$, which is $28 \mathrm{~m}$ less compared to the model with KS5 unfractured. Moreover, the degree of the strong mine pressure indeced by KS4 breaking is reduced.

The vertical displacement of the immediate roof next to the supports during the breakage of KS4 and KS5 in the absence and presence of KS5 fracturing is shown in Fig. 6. As can be seen, when the high-level KS5 is not subjected to $\mathrm{GF}$, the breakage of KS4 results in a maximum sinking of $2.5 \mathrm{~m}$ in the immediate roof, which will probably cause the supports to crash on the working face. After KS5 is fractured from the ground, the vertical displacement of the immediate roof caused by the breakage of KS4 is reduced significantly to $0.45 \mathrm{~m}$, and the KS5 rotation process causes barely any motion of the underlying strata. Subjecting the high-level hard strata to GF has a significant effect on reducing the strong mine pressure in the working face.

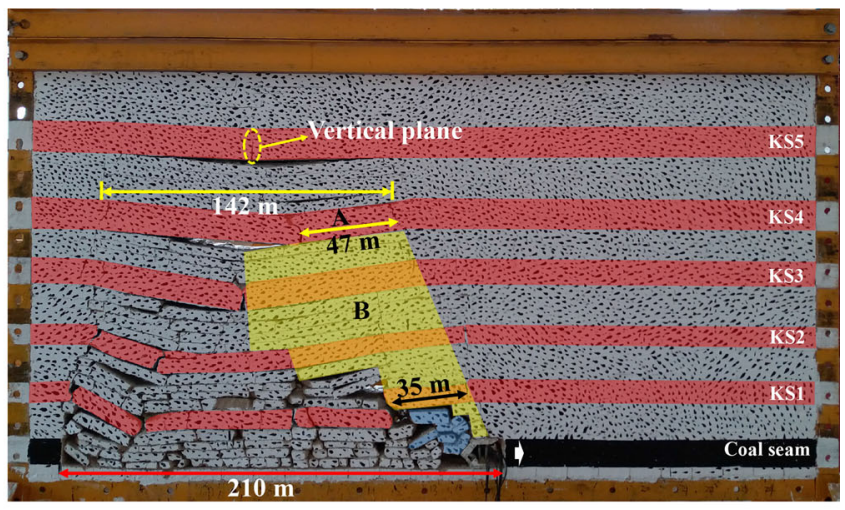

(b)

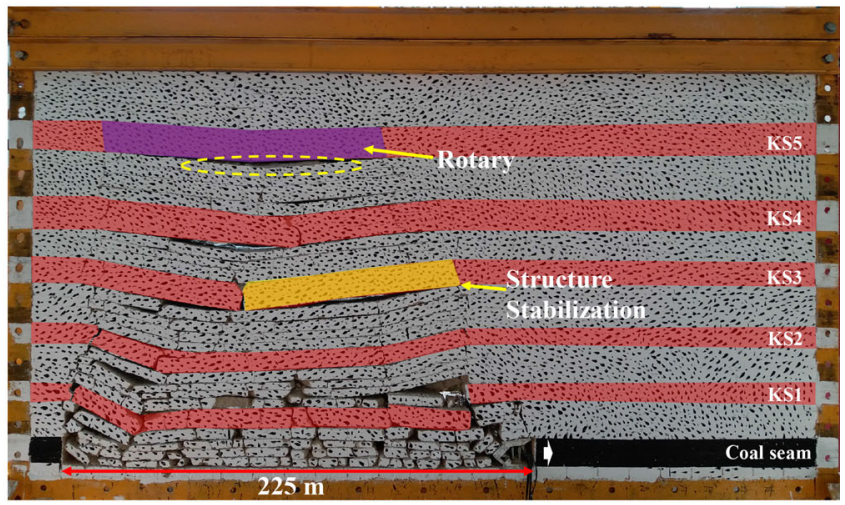

(d)

Fig. 4 Characteristics of overburden breaking: a the first breakage of KS4 (KS5 unfractured); b the first breakage of KS4 (KS5 fractured); $\mathbf{c}$ the first breakage of KS5 (KS5 unfractured); $\mathbf{d}$ the first breakage of KS5 (KS5 fractured) 

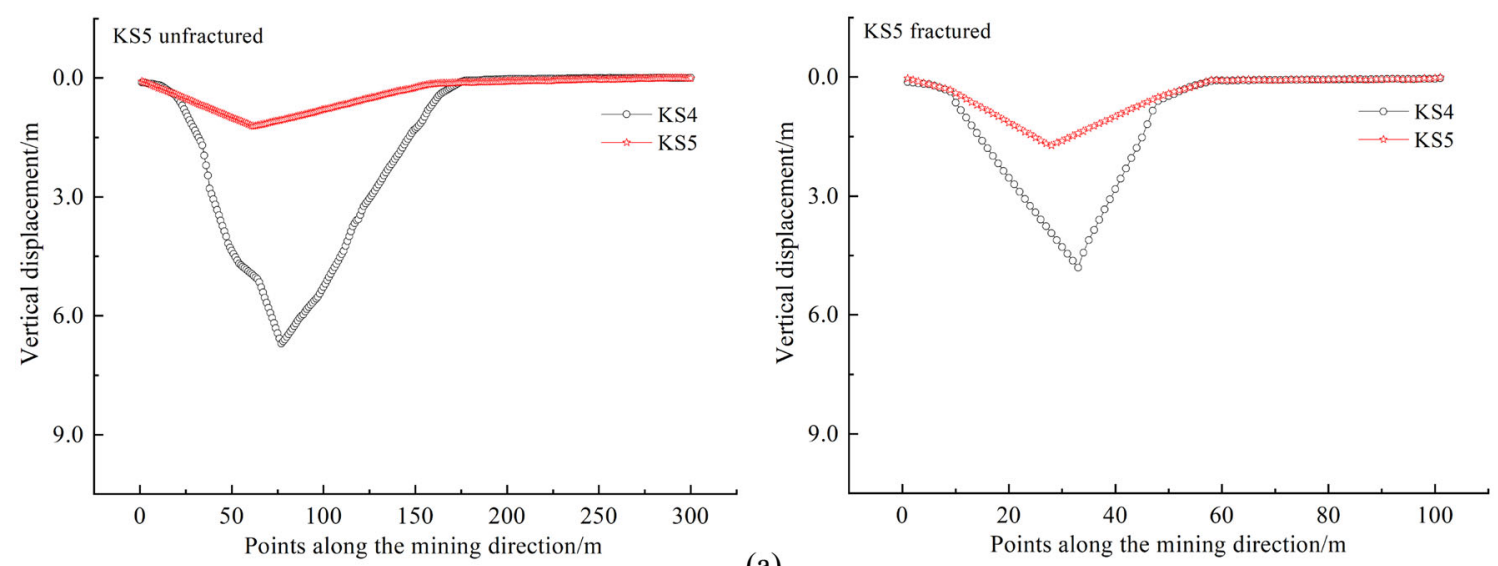

(a)
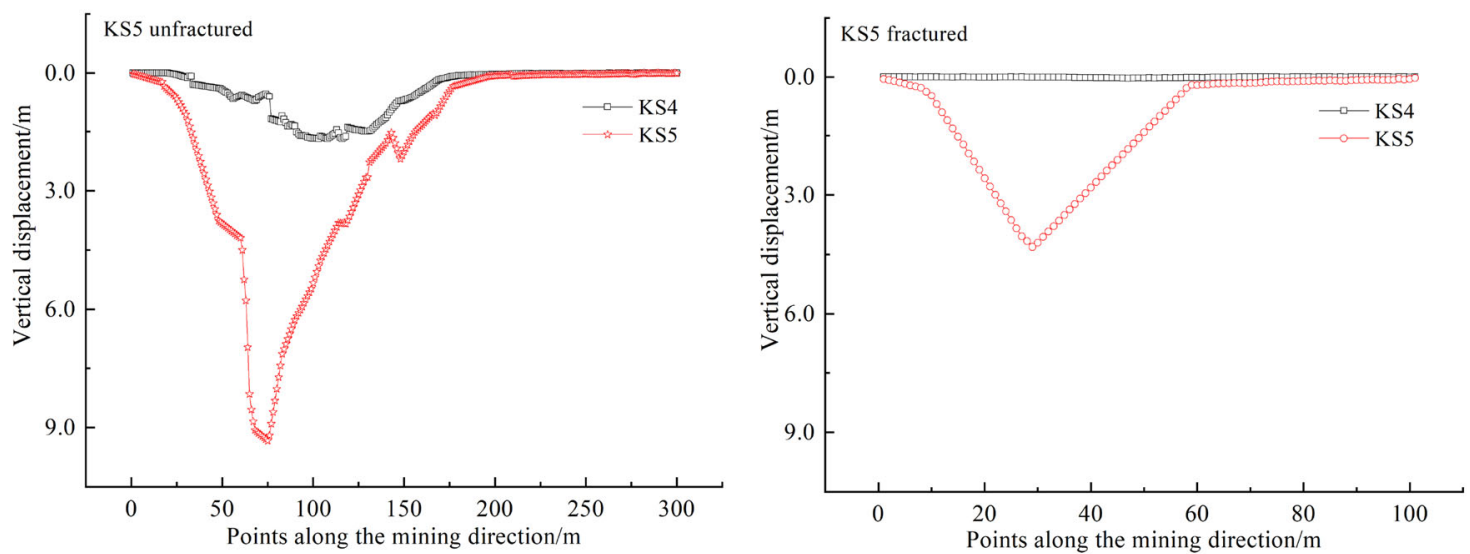

(b)

Fig. 5 Vertical displacement caused by KS5 fracturing: vertical displacement changes during a KS4 and b KS5 breaking

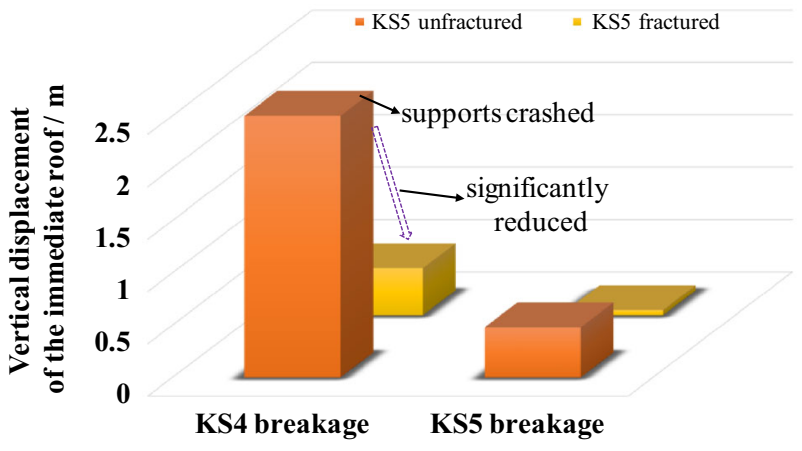

Fig. 6 Comparison of displacement of immediate roof during KS4 and KS5 breaking

\subsubsection{Control effects of overburden movement space}

The experimental research shows that subjecting the highlevel KS5 to GF helps to reduce the breaking step of KS5 and the lower key strata, thereby reducing the influence range during the breakage of high-level thick and hard rock strata and avoiding the formation of excessive structures in the overlying large space. The degree of strong ground pressure in the working face is reduced, and the spatial structure of the overlying rock before and after KS5 fracturing are shown in Fig. 7.

It can be seen from Fig. 7a, c that when KS5 is not fractured, the large structural dimensions in the overburden after the high-level key layers KS4 and KS5 break are 210 and $165 \mathrm{~m}$ and 225 and $165 \mathrm{~m}$, respectively, and after KS5 is fractured, the structural sizes are reduced to 210 and $135 \mathrm{~m}$ and 225 and $120 \mathrm{~m}$, respectively. The GF action reduces the spatial influence range of the high-level hard strata breakage. The area of the overlying strata that acts on the working face supports is denoted as $S$, and the values for $S$ after KS4 and KS5 breakage before and after KS5 fracturing are given in Table 2.

Table 2 shows clearly that the GF decreases the area $S$ in KS4 and KS5 breakage, and the area $S$ of KS4 breakage is reduced to $81.3 \%$. The GF has the most 


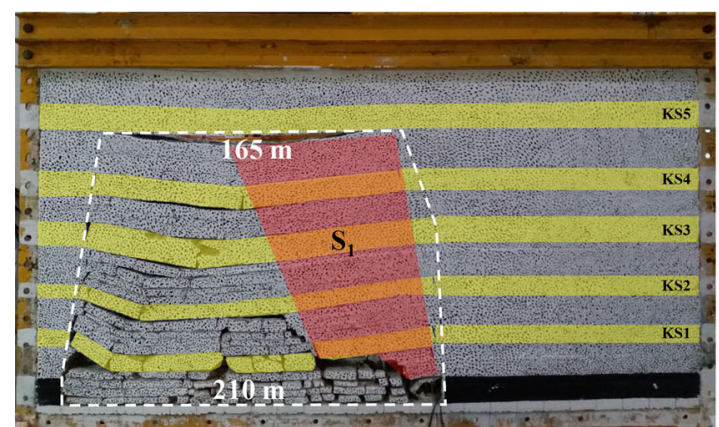

(a)

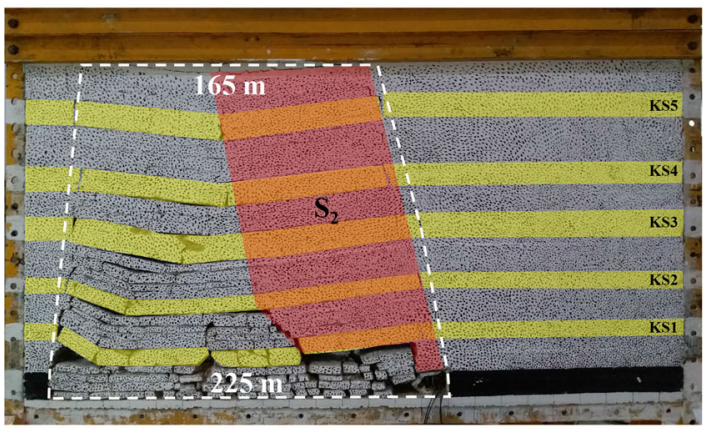

(c)

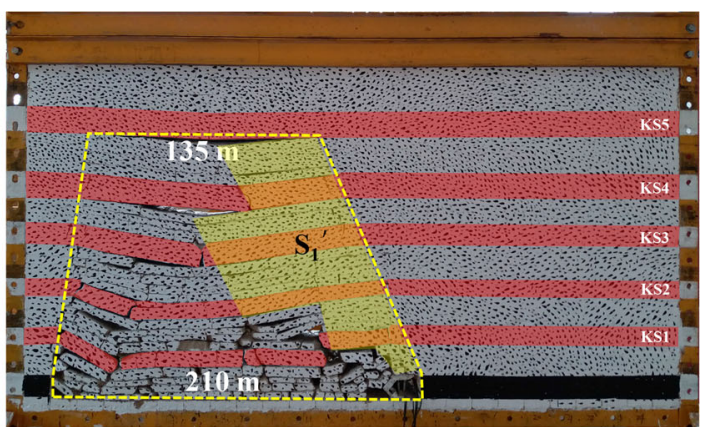

(b)

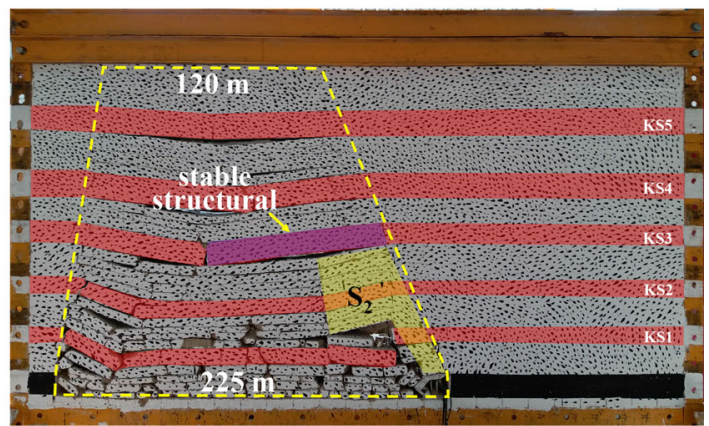

(d)

Fig. 7 Overburden space structure associated with breakage of KS4 and KS5: a breakage of KS4 (KS5 unfractured); b breakage of KS4 (KS5 fractured); $\mathbf{c}$ breakage of KS5 (KS5 unfractured); d rotation of KS5 (KS5 fractured)

Table 2 Statistics for overburden area $S\left(\mathrm{~m}^{2}\right)$

\begin{tabular}{llll}
\hline No. & Item & KS4 breakage & KS5 breakage \\
\hline 1 & KS5 unfractured & $S_{1}=4643.78$ & $S_{2}=6638.08$ \\
2 & KS5 fractured & $S_{1}{ }^{\prime}=3774.06$ & $S_{2}{ }^{\prime}=1062.97$ \\
3 & Ratio $\left(S^{\prime} / S\right)$ & $81.3 \%$ & $16.01 \%$ \\
\hline
\end{tabular}

significant control effect on the mine pressure caused by KS5, and the area $S$ of KS5 breakage is reduced significantly to $16.01 \%$, which reduces significantly the longwall hydraulic support load.

In summary, it can be seen that after KS5 is subjected to $\mathrm{GF}$, the broken structure of KS5 is changed, and its stable rock stratum structure is no longer present. The rotation process of the KS5 structure is sluggish, which significantly reduces the pressure effect of KS5. In addition, after KS5 is fractured, the load acting on the underlying strata is increased, thereby decreasing the breaking span. However, KS5 does not rotate synchronously with the underlying strata, and so it does not increase the pressure strength of the underlying strata. By contrast, the pressure strength of the underlying hard strata (i.e., KS4) decreases with the decrease in the breaking step.

\section{Engineering application}

The 8218 working face of the Tashan coal mine in the Datong mining area was selected as the test site. The geological conditions of that working face are similar to those of the 8101 working face. The 8218 working face is 230-m long, the strike length is $2894 \mathrm{~m}$, and the thickness, burial depth, and inclination of the coal seam are 15-22 m, 414.5-632.1 $\mathrm{m}$, and $2^{\circ}$, respectively. Top-coal caving is used as the mining method. The coal seam is covered with multiple hard rock layers that are mostly lithologically compact and medium-sized and coarse-grained sandstones. In particular, there is 20-m-thick hard sandstone at $110 \mathrm{~m}$ vertically above the coal seam. According to $\mathrm{Yu}$ et al. (2019) and Gao (2018), when mining an extra-thick coal seam, when the ratio of the distance between the hard strata and coal seam to the coal seam thickness is 5.3-7.3, the mine pressure of the hard strata breaking is the strongest. This is the main factor causing the strong mining pressure of the working face, based on which the 20-m-thick hard rock formations are targeted as the fractured layers.

A horizontal well can realize multistage fracturing, for which the control range is wide and the fracturing effect is good. Given the need to achieve high-efficiency control of high-level thick and hard rock layers, a horizontal well is adopted in this experiment. 


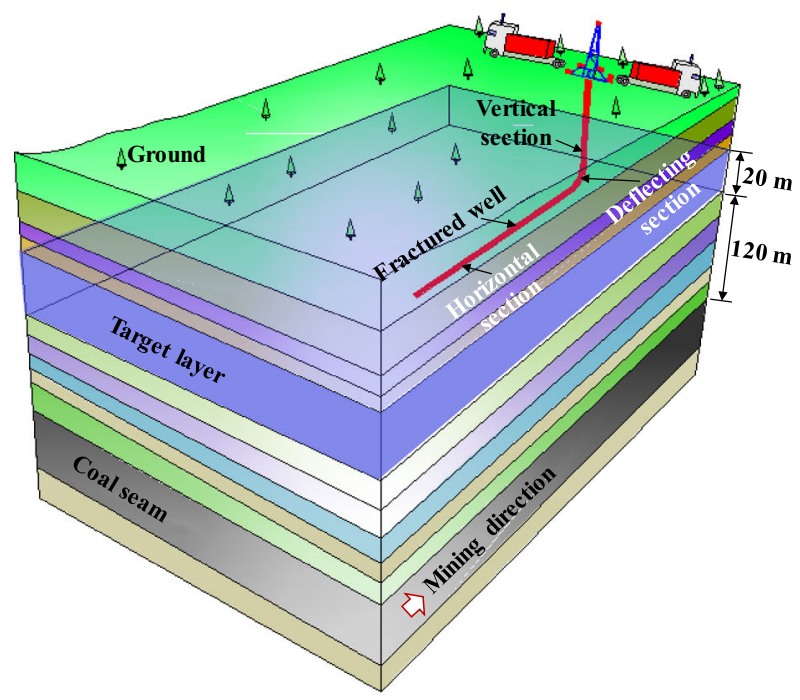

(a)

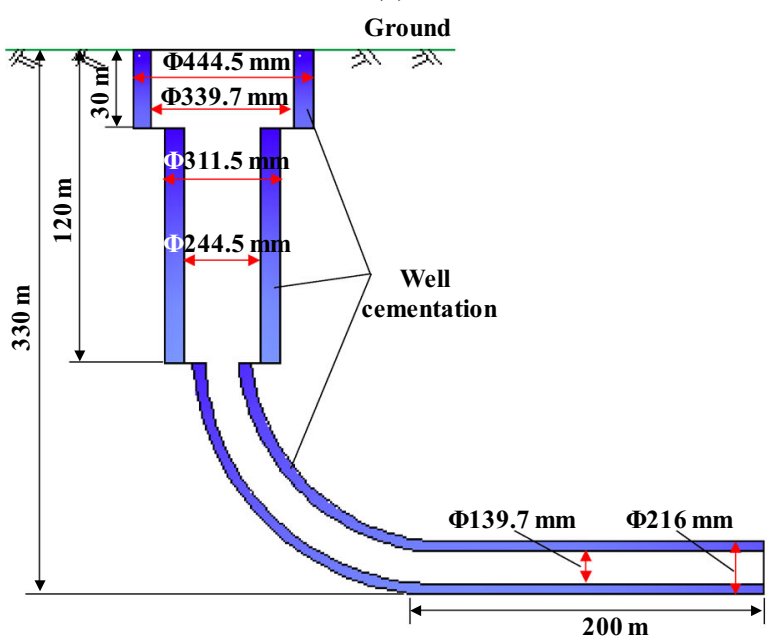

(b)

Fig. 8 Structural representation of hydraulically fractured well: a location; b structure

\subsection{Fracturing process and equipment}

The horizontal fracturing well comprises a vertical section, a deflecting section, and a horizontal section. The wellhead is located $99 \mathrm{~m}$ from the stop line of the working face, $105 \mathrm{~m}$ from the return airway, and $125 \mathrm{~m}$ from the intake airway. The horizontal section of the fracturing well extends parallel to the mining direction of the working face but opposite to the mining advancing direction. The vertical section of the fracturing well has a three-level structure: the first level is drilled to $30 \mathrm{~m}$ with a $\phi 444.5-\mathrm{mm}$ drill bit, and a $\phi 339.7 \mathrm{~mm} \times 9.65 \mathrm{~mm}$ surface casing is inserted; the second level is drilled to $120 \mathrm{~m}$ with a $\phi$ $311.5-\mathrm{mm}$ drill bit, and a $\phi 244.5 \mathrm{~mm} \times 8.94 \mathrm{~mm}$ intermediate casing is inserted; the third level is drilled to $650 \mathrm{~m}$ with a $\phi 216-\mathrm{mm}$ drill bit, and a $\phi 139.7 \mathrm{~mm} \times$
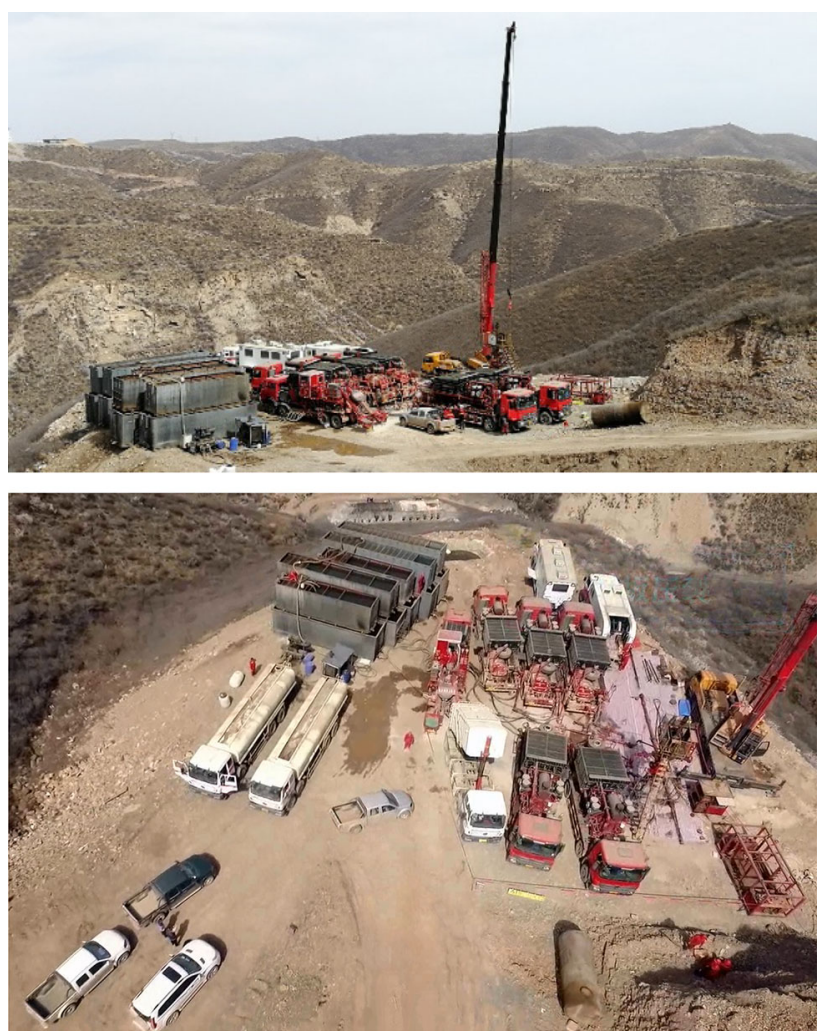

Fig. 9 Layout of construction site for ground fracturing (GF)

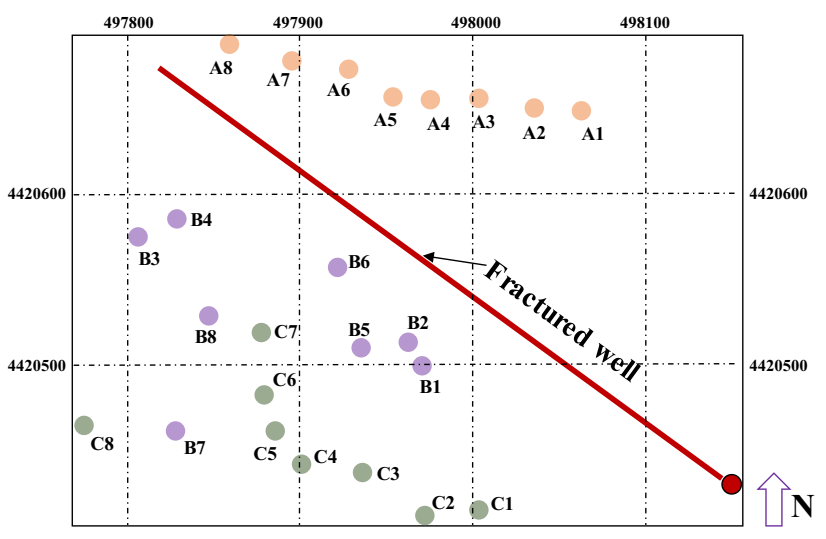

Fig. 10 Position layout of detectors

$7.72 \mathrm{~mm}$ intermediate casing is inserted. The deflecting section is $330-\mathrm{m}$ long and the horizontal section is $200-\mathrm{m}$ long. The relative positions of the fracturing well and working face and the fracturing well structure are shown in Fig. 8.

The area around the target fractured strata was perforated by drilling numerous small holes in the walls of the fracturing well; these allow the fracturing fluid to expand, thereby achieving the fracturing purpose. The target strata were designed to be fractured in three stages in the horizontal section. To ensure the fracturing effect, the perforation density in the fractured zone was designed to be as 
Table 3 Coordinates of detectors

\begin{tabular}{llll}
\hline Detector & $X(\mathrm{~m})$ & $Y(\mathrm{~m})$ & $Z(\mathrm{~m})$ \\
\hline Wellhead & 498,150 & 4420,432 & 1490 \\
A1 & 498,064 & 4420,648 & 1452 \\
A2 & 498,036 & 4420,649 & 1446 \\
A3 & 498,004 & 4420,655 & 1438 \\
A4 & 497,976 & 4420,654 & 1434 \\
A5 & 497,954 & 4420,656 & 1435 \\
A6 & 497,929 & 4420,672 & 1438 \\
A7 & 497,896 & 4420,677 & 1434 \\
A8 & 497,860 & 4420,686 & 1429 \\
B1 & 497,971 & 4420,500 & 1512 \\
B2 & 497,963 & 4420,514 & 1514 \\
B3 & 497,807 & 4420,575 & 1496 \\
B4 & 497,830 & 4420,585 & 1482 \\
B5 & 497,936 & 4420,511 & 1479 \\
B6 & 497,922 & 4420,557 & 1485 \\
B7 & 497,829 & 4420,463 & 1523 \\
B8 & 497,848 & 4420,530 & 1492 \\
C1 & 498,004 & 4420,417 & 1545 \\
C2 & 497,973 & 4420,414 & 1540 \\
C3 & 497,937 & 4420,438 & 1540 \\
C4 & 497,902 & 4420,443 & 1520 \\
C5 & 497,885 & 4420,460 & 1521 \\
C6 & 497,880 & 4420,484 & 1519 \\
C7 & 497,878 & 4420,520 & 1488 \\
C8 & 497,775 & 1536 \\
\hline & & &
\end{tabular}

high as 16 per meter. When the GF was performed, five pump trucks, one sand mixer, one instrument vehicle, five liquid tank trucks, and one sand tank truck were used. The reserve fracturing water was $2000 \mathrm{~m}^{3}$. The GF site construction is shown in Fig. 9.

In the first, second, and third stages, the maximum bursting pressure was $12.46,10.00$, and $10.33 \mathrm{MPa}$, respectively, and the total liquid volume was 470.9, 549.0, and $576.9 \mathrm{~m}^{3}$, respectively.

\subsection{Analysis of fracturing effect}

\subsubsection{Monitoring of crack propagation}

To describe the law governing the hydraulic crack propagation, detectors were placed on the ground to monitor the microseismic wave signals during the fracturing process. Taking the fracturing well as the center, the detectors were arranged around the fracturing well as shown in Fig. 10.

The positions of the detectors are listed in Table 3. The detectors were positioned accurately with high-precision
GPS (the maximum uncertainty of which is $3.0 \mathrm{~m}$ ), and the detectors were buried deeper than $30 \mathrm{~cm}$.

After the first stage of fracturing, the crack propagation pattern was monitored, as shown in Fig. 11a; this shows that the crack propagation direction was $\mathrm{NE} 90^{\circ}$, with the length of $134 \mathrm{~m}$ and $62 \mathrm{~m}$ in two different direction, respectively. After the second stage of fracturing, the crack propagation was monitored, as shown in Fig. 11b; this shows that the crack propagation direction was $\mathrm{NE} 55^{\circ}$, the crack spread in two opposite directions, the expansion lengths were 98 and $118 \mathrm{~m}$, respectively, and the total length of the crack was $216 \mathrm{~m}$. After the third stage of fracturing, the crack propagation was monitored, as shown in Fig. 11c; this shows that the crack propagation direction was $\mathrm{NE} 50^{\circ}$, the cracks extended in two opposite directions, the expansion lengths were 118 and $98 \mathrm{~m}$, respectively, and the total crack length was $216 \mathrm{~m}$.

The morphological characteristics of the cracks after fracturing thrice in the horizontal section are listed in Table 4. The fracturing crack that extended in the horizontal direction was 216-m long, which exceeds the length of the working face. The expansion direction was approximately perpendicular to the horizontal section of the fracturing well. The crack that extended in the vertical direction was around 50-m long, and the crack expansion range was wide, completely covering the thickness range of the fractured target layer.

\subsubsection{Ground-pressure control effect}

To monitor the rock mass deformation and stress concentration in the stope after the GF in the range of crack expansion, the hydraulic supports in the middle of the working face were selected to note the resistance of the working face in the normal mining section and fractured crack extension section. The roadway-deformation monitoring points were also arranged at intervals of $10 \mathrm{~m}$ in the normal mining section and fractured crack extension area in the roadway, and they were recorded as No. 1-6, respectively, to monitor the deformation of the roadway, as shown in Fig. 12.

The roadway deformation and support resistance before and after the working face entered the GF control zone are shown in Fig. 13. The deformation characteristics of the roadway in front of the working face at $20 \mathrm{~m}$ are shown in Fig. 13a. The roadway deformation at measuring points No. 1 and 3 were large, mainly due to the large mining thickness of the coal seam. The roadway deformation was significant in the advanced $20 \mathrm{~m}$ of the working face, and the extent of the roof-to-floor and two-side convergence was more than $1500 \mathrm{~mm}$. The phenomenon of single prop bended was obvious. When the working face entered the GF control zone, the roadway deformation in advance was 

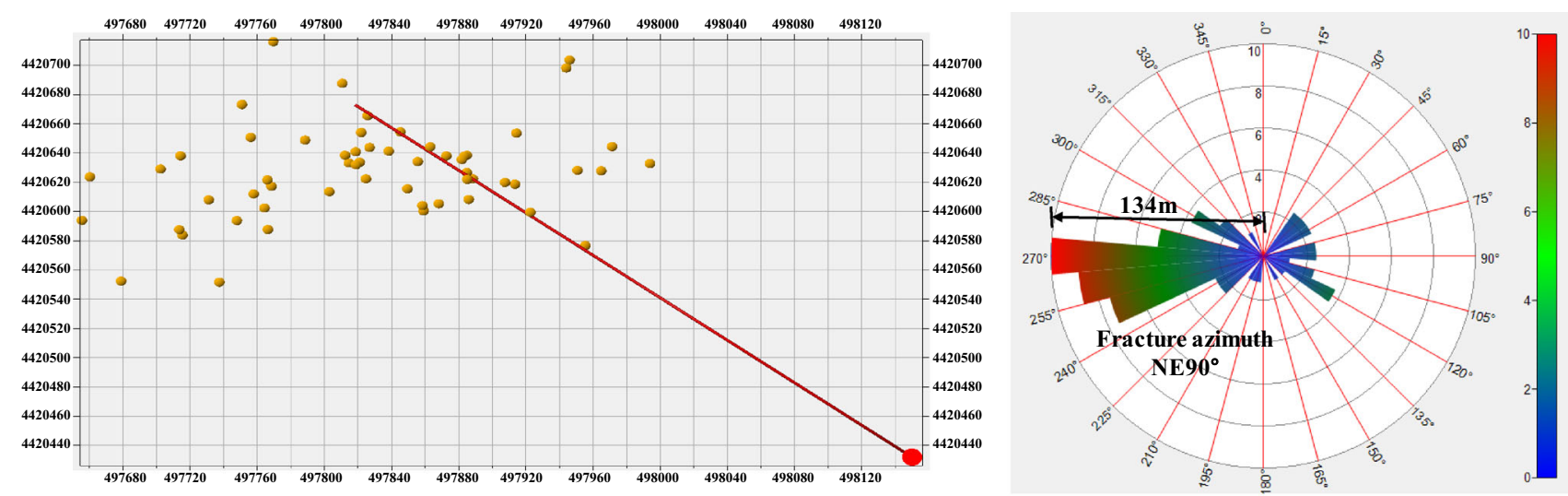

(a)
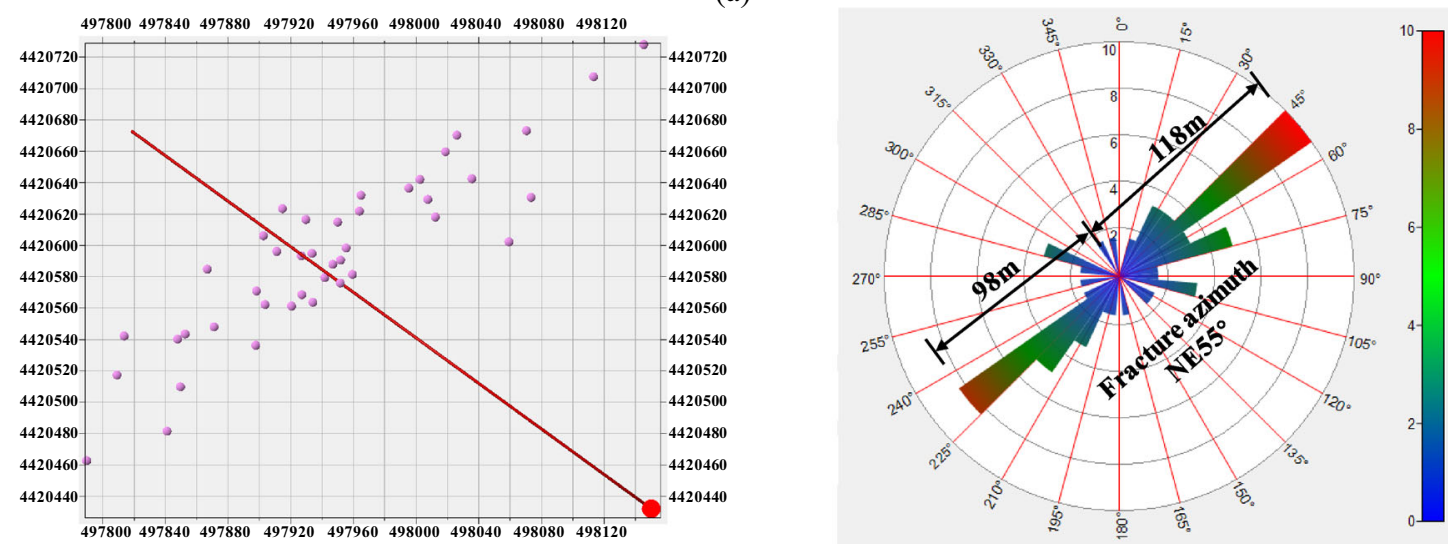

(b)
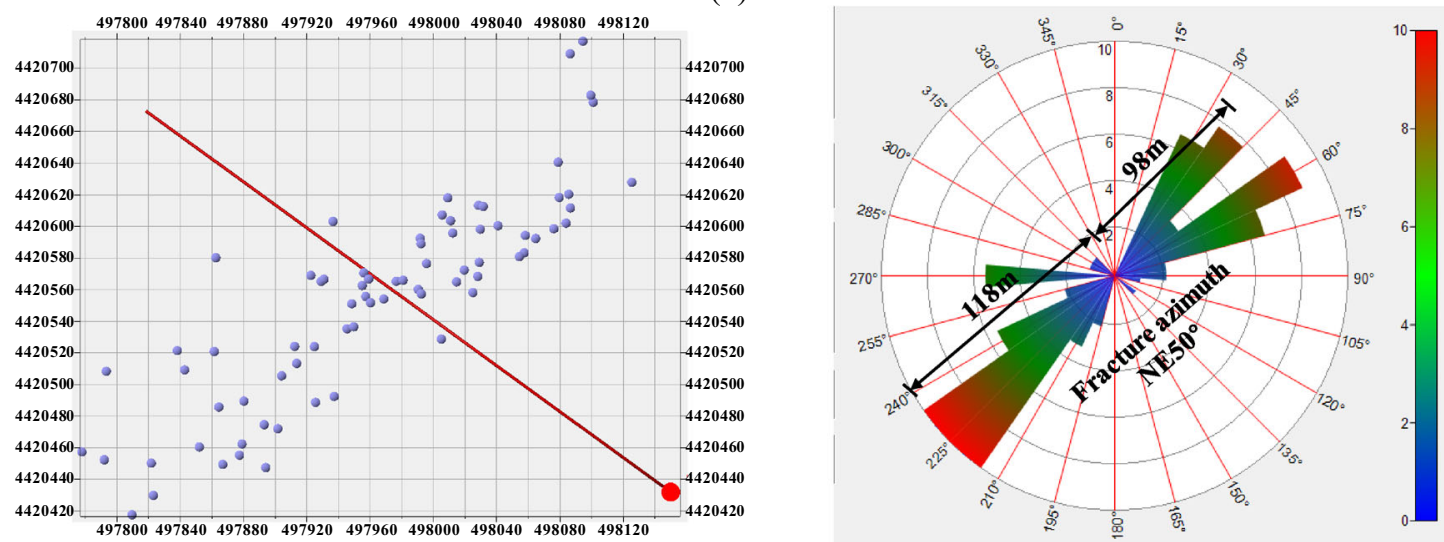

(c)

Fig. 11 Crack expansion in the three fracturing stages: crack expansion in a TL1, b TL2, and c TL3

Table 4 Crack morphology statistics of the three stages

\begin{tabular}{|c|c|c|c|c|c|c|}
\hline \multirow[t]{2}{*}{ No. } & \multirow[t]{2}{*}{ Stage } & \multicolumn{2}{|c|}{ Crack length (m) } & \multicolumn{2}{|c|}{ Crack height (m) } & \multirow[t]{2}{*}{ Propagation direction $\left({ }^{\circ}\right)$} \\
\hline & & Left & Right & Upward & Downward & \\
\hline 1 & First stage & 134 & 62 & 22 & 21 & NE90 \\
\hline 2 & Second stage & 98 & 118 & 24 & 26 & NE55 \\
\hline 3 & Third stage & 118 & 98 & 22 & 25 & NE50 \\
\hline
\end{tabular}




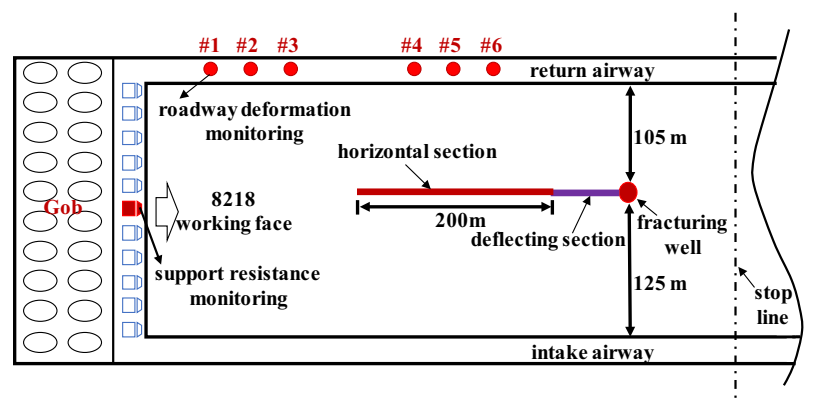

Fig. 12 Layout of ground-pressure monitoring

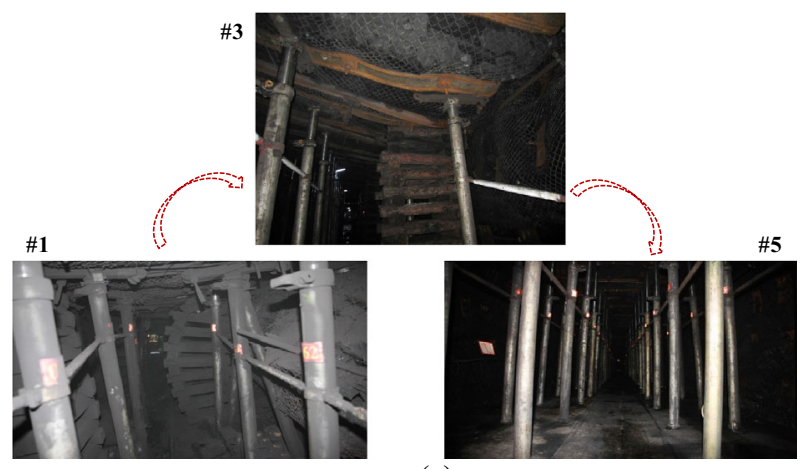

(a)

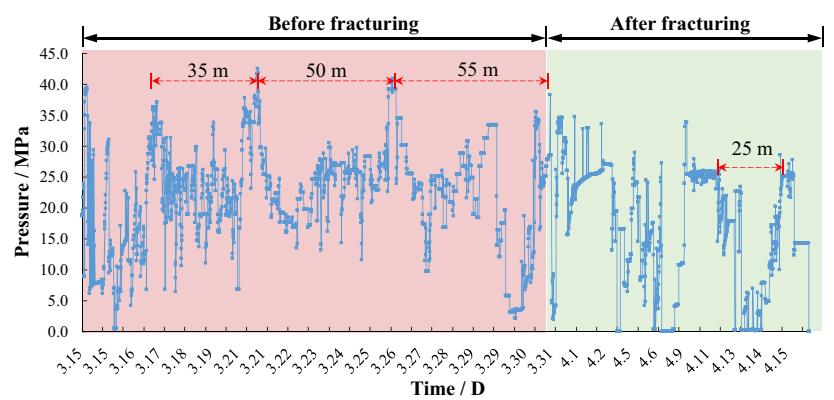

(b)

Fig. 13 Characteristics of a roadway deformation and b support resistance influenced by GF

highly controlled. Taking measuring point No. 5 as an example, the roadway deformation was less than $300 \mathrm{~mm}$, no prop exhibited bending, and the roadway maintenance was in excellent condition.

The characteristics of the support resistance before and after the working face entered the GF control zone are shown in Fig. 13b. This shows clearly that the periodic weighting pace of the working face was in the range of 35-55 $\mathrm{m}$ before the working face entered the GF control zone. Affected by the breakage and instability of the hard roofs, the compressive strength was up to $43 \mathrm{MPa}$, which had an obvious influence on the working face. When the working face was mined into the GF control zone, there were no obvious weighting step characteristics, and the maximum shield pressure dropped to $30 \mathrm{MPa}$.
In summary, after the high-level hard and thick strata were subjected to GF, their integrity and structural characteristics were destroyed, which reduced the energy intensity of the strata breakage. The surrounding rock failure and compressive strength of the supports were controlled significantly. As can be seen, GF reduced the stress environment in the stope and controlled the deformation of the surrounding rock. This is a new and powerful approach to controlling hard roofs in coal mining areas.

\section{Conclusions}

The present research has shown that when mining an extrathick coal seam, the breaking and instability of thick and hard strata at a vertical distance of $100 \mathrm{~m}$ above the coal seam are the main causes of strong ground pressure. This paper has proposed using GF to weaken the high-level hard roofs using only clear water, which is economical and environmentally friendly and has operability.

Physical simulation studies showed that the action of ground-fractured high-level hard strata reduces the breakage steps and changes the structural characteristics of the strata. The breakage of the high-level hard strata is no longer a fast high-intensity process but rather one of slow rotation, which reduces the strata breaking strength and mining pressure. The control effect of GF is remarkable.

A horizontal fracturing well was used for an on-site fracturing test. The targeted fracturing layer was $20-\mathrm{m}$ thick and located $110 \mathrm{~m}$ vertically above the coal seam. The fracturing process was performed in three stages. Microseismic monitoring showed that the horizontal extension length of the fracturing crack reached $216 \mathrm{~m}$, the height reached $50 \mathrm{~m}$, and the expansion range was wide. The GF released the strata stress concentration and changed the strata structure and its mining pressure action. After the GF, the roadway deformation and support resistance of the 8218 working face were highly controlled, and the GF control effect was remarkable.

The successful test with the horizontal fracturing well shows that the control range and fracturing effect of GF are remarkable, which provides a new approach for controlling high-level hard and thick strata in coal mines and is of tremendous significance. Also, horizontal fracturing wells can achieve multistage fracturing with strong controllability and operability, and they have broad application prospects.

Author contributions Rui Gao designed the study, participated in data analysis, and carried out sequence alignments. Tiejun Kuang participated in the design of the study and drafted the manuscript. Yanqun Zhang carried out the physical simulation and analyzed the data. Wenyang Zhang and Chunyang Quan helped draft the 
manuscript and collected the field measurement data. All authors gave final approval for publication.

Funding This work was supported by the State Key Research Development Program of China (Grant No. 2018YFC0604500, 2018YFC0604506), by the China Postdoctoral Science Foundation (Grant No. 2019M651080), as an applied basic research Project of Shanxi Province (Grant No. 201901D211030), by the Scientific, Technological Innovation Programs of Higher Education Institutions in Shanxi (STIP) (Grant No. 2019L0208), as a Major Program in Shanxi Province (Grant No. 20191101015), and as a Distinguished Youth Funds of National Natural Science Foundation of China (No. 51925402).

Availability of data and materials The data and material in the paper are transparent and available in the paper.

\section{Compliance with ethical standards}

\section{Conflict of interest None.}

Open Access This article is licensed under a Creative Commons Attribution 4.0 International License, which permits use, sharing, adaptation, distribution and reproduction in any medium or format, as long as you give appropriate credit to the original author(s) and the source, provide a link to the Creative Commons licence, and indicate if changes were made. The images or other third party material in this article are included in the article's Creative Commons licence, unless indicated otherwise in a credit line to the material. If material is not included in the article's Creative Commons licence and your intended use is not permitted by statutory regulation or exceeds the permitted use, you will need to obtain permission directly from the copyright holder. To view a copy of this licence, visit http://creativecommons. org/licenses/by/4.0/.

\section{References}

Bandyopadhyay K, Mallik J, Ghosh T (2020) Dependence of fluid flow on cleat aperture distribution and aperture-length scaling: a case study from Gondwana coal seams of Raniganj formation, Eastern India. Int J Coal Sci Technol 7(1):133-146

Bednarek L, Majcherczyk T (2020) An analysis of rock mass characteristics which influence the choice of support. Geomech Eng 21(4):371-377

Cheng XY (2019) Damage and failure characteristics of rock similar materials with pre-existing cracks. Int J Coal Sci Technol 6(4):505-517

Gao R (2018) The mechanism of ground pressure induced by the breakage of far-field hard strata and the control technology of ground fracturing. Dissertation, China University of Mining and Technology

Ge ZL, Mei XD, Lu YY, Tang JR, Xia BW (2015) Optimization and application of sealing material and sealing length for hydraulic fracturing borehole in underground coal mines. Arab J Geosci $8: 3477$

Guo WB, Liu CY, Wu FF, Yang PJ, Wu SF (2014) Analyses of support crushing accidents and support working resistance in large mining height workface with hard roof. J Chin Coal Soc 39(7):1212-1219

Ju JF, Xu JL (2013) Structural characteristics of key strata and strata behavior of a fully mechanized longwall face with $7.0 \mathrm{~m}$ height chocks. Int J Rock Mech Min Sci 58:46-54
Lan YW, Gao R, Yu B, Meng B (2018) In situ studies on the characteristics of strata structures and behaviors in mining of a thick coal seam with hard roofs. Energies 11(9):2470

Li HM, Jiang DJ, Li DY (2014) Analysis of ground pressure and roof movement in fully-mechanized top coal caving with large mining height in ultra-thick seam. J Chin Coal Soc 39(10):1956-1960

Li Z, Xu JL, Ju JF, Zhu WB, Xu JM (2018) The effects of the rotational speed of voussoir beam structures formed by key strata on the ground pressure of stopes. Int J Rock Mech Min Sci 108:67-79

Lu YY, Cheng L, Ge ZL, Xia BW, Li Q, Chen JF (2015) Analysis on the initial cracking parameters of cross-measure hydraulic fracture in underground coal mines. Energies 8(7):6977-6994

Lu YY, Gong T, Xia BW, Yu B, Huang F (2018) Target stratum determination of surface hydraulic fracturing for far-field hard roof control in underground extra-thick coal extraction: a case study. Rock Mech Rock Eng 52(8):2725-2740

Ning JG, Wang J, Jiang LS, Jiang N, Liu XS, Jiang JQ (2017) Fracture analysis of double-layer hard and thick roof and the controlling effect on strata behavior: a case study. Eng Fail Anal 81:117-134

Sampath KHSM, Perera MSA, Ranjith PG, Matthai SK, Rathnaweera $\mathrm{T}$, Zhang $\mathrm{G}$, Tao $\mathrm{X}$ (2017) $\mathrm{CH}_{4}-\mathrm{CO}_{2}$ gas exchange and supercritical $\mathrm{CO}_{2}$ based hydraulic fracturing as CBM production-accelerating techniques: a review. $\mathrm{J} \mathrm{CO}_{2}$ Utiliz 22:212-230

Tan YL, Liu XS, Shen B (2018) New approaches to testing and evaluating the impact capability of coal seam with hard roof and/ or floor in coal mines. Geomech Eng 14(4):367-376

Wang J, Ning JG, Qiu PQ (2019) Microseismic monitoring and its precursory parameter of hard roof collapse in longwall faces: a case study. Geomech Eng 17(4):375-383

Wang J, Yang JX, Wu FF, Hu TF, Faisal AS (2020) Analysis of fracture mechanism for surrounding rock hole based on waterfilled blasting. Int J Coal Sci Technol 7(4):704-713

Xia BW, Jia JL, Yu B, Zhang X, Li XL (2017) Coupling effects of coal pillars of thick coal seams in large-space stopes and hard stratum on mine pressure. Int J Min Sci Technol 27:965-972

Xie JL, Xu JL (2017) Effect of key stratum on the mining abutment pressure of a coal seam. Geosci J 21(2):267-276

Yang JX, Liu CY, Yu B (2015) Mechanism of complex mine pressure manifestation on coal mining work faces and analysis on the instability condition of roof blocks. Acta Geodyn Geomater 12(1):101-108

Yang JX, Liu CY, Yu B (2017) Application of confined blasting in water-filled deep holes to control strong rock pressure in hard rock mines. Energies 10:1874

Yang JX, Liu CY (2017) Experimental study and engineering practice of pressured water coupling blasting. Shock Vib 2017:5484598. https://doi.org/10.1155/2017/5484598

Yan H, Zhang JX, Zhang S, Zhou N (2018) Physical modeling of the controlled shaft deformation law during the solid backfill mining of ultra-close coal seams. B Eng Geol Environ 2:1-14

$\mathrm{Yu}$ B (2016) Behaviors of overlying strata in extra-thick coal seams using top-coal caving method. J Rock Mech Geotech Eng $8: 238-247$

Yu B, Duan HF (2014) Study of roof control by hydraulic fracturing in full-mechanized caving mining with high strength in extrathick coal layer. Chin J Rock Mech Eng 33(4):778-785

Yu B, Gao R, Kuang TJ, Huo BJ, Meng XB (2019) Engineering study on fracturing high-level hard rock strata by ground hydraulic action. Tunn Undergr Sp Tech 86:156-164

Yu B, Zhao J, Kuang TJ, Meng XB (2015) In situ investigations into overburden failures of a super-thick coal seam for longwall top coal caving. Int J Rock Mech Min Sci 78:155-162 
Yu B, Zhao J, Xiao HT (2017) Case study on overburden fracturing during longwall top coal caving using microseismic monitoring. Rock Mech Rock Eng 50:507-511

Zhang HW, Zhu ZJ, Huo LJ, Chen Y, Huo BJ (2014) Overburden failure height of superhigh seam by fully mechanized caving method. J Chin Coal Soc 39(5):816-821
Zuo JP, Wang JT, Jiang YQ (2019) Macro/meso failure behavior of surrounding rock in deep roadway and its control technology. Int J Coal Sci Technol 6(3):301-319 